\title{
Assessing participation of women in a cervical cancer screening program in Peru
}

\author{
Sylvia C. Robles, ${ }^{1}$ Catterina Ferreccio, ${ }^{2}$ Vivien Tsu, ${ }^{3}$ Jenny Winkler, ${ }^{3}$ \\ Maribel Almonte, ${ }^{4}$ Allison Bingham, ${ }^{3}$ Merle Lewis, ${ }^{5}$ and Peter Sasieni ${ }^{4}$
}

Suggested citation Robles SC, Ferreccio C, Tsu V, Winkler J, Almonte M, Bingham A, Lewis M, Sasieni P. Assessing participation of women in a cervical cancer screening program in Peru. Rev Panam Salud Publica. 2009; 25(3):189-95.

\begin{abstract}
Objective. To assess systemic and individual factors influencing participation of women in a screening program for cervical cancer.

Methods. In November 2000, a new cervical cancer screening program was introduced in the Region of San Martin, Peru. A total of 107683 women, ages 25-49, were eligible for screening. This report covers the initial period from program inception through 31 October 2003. We used data from the program information system to identify systemic factors and individual characteristics influencing women's participation. We conducted a three-step analysis: we assessed systemic factors at the level of micronetworks or group of health centers, we estimated the odds of being a new user (never screened or not screened in the past 5 years) according to sociodemographic characteristics, and we assessed how women learned about the availability of screening services while controlling for influential factors identified in previous analyses.

Results. During the 3-year period, 36759 eligible women attended screening services, for a participation rate of $32.3 \%$. While attendance varied by area and time period, the program attracted 12208 new users. Health care micronetworks with available static screening services had higher participation. New users were more likely than regular users to have less education and to report low use of family-planning services. All other factors being equal, they were also more likely than regular users to hear about screening services from a health care provider.

Conclusion. In this setting, the presence of and contact with health services played a role in increasing the participation in screening of women not previously screened or not screened in the past 5 years.
\end{abstract}

Key words Uterine cervical neoplasm, mass screening, health services accessibility, Peru.

1 World Bank Group, Health Nutrition and Population, Washington, D.C., United States of America. Send correspondence and reprint requests to: Sylvia Robles, World Bank Group, Health Nutrition and Population, $1818 \mathrm{H}$ Street Northwest, Washington, D.C., United States of America; telephone: 202-473-9466; fax: 202-522-3489; e-mail: srobles@worldbank.org

2 Catholic University, Public Health, Santiago, Chile.

3 PATH, Seattle, Washington, United States of America.

4 Cancer Research, Centre Epidemiology, Mathematics and Statistics, London, United Kingdom.

5 Pan American Health Organization, Nassau, Bahamas.
Latin America exhibits one of the highest incidence and mortality rates from cervical cancer in the world. In this region, age-adjusted incidence rates range from 30 to 60 per 100000 and account for nearly 47.1 disability-adjusted life years (1), in spite of the availability of cervical cytology in these countries for at least 40 years. One cornerstone of cervical cancer screening is to ensure participation of women at risk. To achieve this goal, organized screening programs rely on a variety of call-recall modalities to invite the participation of women, which assumes the existence of some form of registration of the base population and the possibility of locating women by mail or telephone (1). This is often difficult and costly in developing countries, particularly in low-resource areas (2).

In the context of a new cervical cancer prevention program, introduced in 2000 
in the region of San Martin, Peru, women were invited to participate in screening. The program was named TATI, a Spanish acronym for screening and immediate treatment. We established an evaluation project with the following overall objectives: (1) to implement and evaluate a screening and treatment model for the prevention of cervical cancer, based on visual inspection of the cervix uteri, in a resource-constrained setting; and (2) to assess the possibility of achieving $80 \%$ participation of the target population in 3 years, as required by the guidelines of the Peruvian Ministry of Health. Before this time, as in other Latin American countries, cytology-based opportunistic screening was available in public health services $(3,4)$.

In Peru, in this setting, there were no statistics on the proportion of eligible women screened, nor was there any information about women not being reached. Screening services were offered at women's request and at the suggestion of health care providers but not through systematic outreach or in-reach efforts. When project TATI started, we implemented an information system for the participating health services. In this paper, we use readily available data from this information system to report on participation in TATI of women who were never or infrequently screened (new users).

\section{MATERIALS AND METHODS}

\section{Study setting}

The study was conducted in the Peruvian Amazonia in the Region of San Martin. The estimated population for the year 2000 was 769331 inhabitants. This region, one of the decentralized Directorates of Health within the Peruvian health care system, is divided into 11 health networks and 57 health micronetworks. A health micronetwork consists of one or two health care centers, staffed by a physician, nurses, and community health workers, and five or six health posts, staffed by nurses. In most cases, three to six micronetworks form a health network. Altogether, there are 51 health centers and 280 health posts. The project trained one physiciannurse team per network and equipped health services to provide cervical cancer screening and treatment services. A detailed description of the full study and activities conducted in Peru by the Pan American Health Organization, PATH, and the Ministry of Health is published elsewhere (5).

\section{Eligible population}

The target population was 107683 women, ages 25-49 years, residing in San Martin. Although national guidelines limit screening to ages 30-49 years, we included the age group 25-29 at the request of the Ministry of Health to assess the possibility of extending screening to this younger group. We used census data available to the reproductive health program to identify the population of women within the age range by locality. At the point of service, through a short interview, a nurse assessed eligibility for screening. Women were not eligible if previously diagnosed with cervical cancer, never had sexual intercourse, had a total hysterectomy or conisation of the cervix uteri, or were pregnant at the time of the interview. Nurses assessed whether a woman was pregnant by asking for the date of the last menstrual period; if it was more than 6 weeks ago, they asked women to return for screening 3 months after delivery or termination of pregnancy.

\section{Outreach, awareness-raising, and recruitment procedures}

At the level of micronetworks, 79 promotion teams were established to encourage participation in the program. Each team included a community health worker from a local health center and a community leader. These teams carried out educational activities locally and through mobile campaigns in advance of a visit by a screening team to a health post. Women were invited to participate in cervical cancer screening during routine visits to the health center and through outreach activities by community promotion teams. These activities included the following: (1) holding awareness-raising meetings on cervical cancer prevention and (2) leading more in-depth education sessions on the topics of "knowing my body," vaginal infections, cervical cancer, and self-esteem. These teams also organized advisory groups of local dignitaries and community leaders to strengthen communitylevel support for activities to prevent cervical cancer.

\section{Project management}

The project was conducted in partnership with the Ministry of Health; recruitment started on 1 November 2000 and continued through 31 October 2003, expanding for a total of 36 months. The project was approved by the Ethical Committee of the Ministry of Health of Peru and the Ethics Committee of the Pan American Health Organization. An office was established in Tarapoto, San Martin, to coordinate the fieldwork, monitor progress, supervise screening activities in health centers, supervise community promotion teams, perform data entry, and maintain the database of the information system. The local team prepared monthly reports for the national and international teams to facilitate ongoing review. No payments beyond their regular government salaries were made to personnel from the Ministry of Health, including those providing direct patient care, so that conditions could be as close to "real life" as possible.

\section{Data collection and management}

To prevent data collection overload at the point of service, forms for new procedures were designed and incorporated as part of the information system of the Ministry of Health. A nurse conducted an interview to obtain information on age, marital status, years of education, tobacco use, pregnancies, parity, lifetime number of sexual partners, having ever visited health services for contraception, and how they learned of screening services. Data drawn from the database of community promotion activities and from project monitoring records for each micronetwork included the following: mobile screening campaigns conducted; months screening service was available in each health care center; number of health services per micronetwork; number of advisory group meetings; accessibility to nearest screening facility through an assessment score, which included transportation, distance, and time; and record of each educational session conducted.

In each network, health centers and health posts sent forms to the lead health center, where forms were reviewed for completeness, and missing information was directly requested from the referring health center. The forms were then sent to the TATI office where trained 
staff reviewed, coded, and entered the information into a database. We established a data entry protocol and designed a program to identify inconsistencies as well as duplicates should women return for screening during the 3-year period.

\section{Data analysis}

After a description of the participation of women in the screening program over the period under study, we conducted a three-step analysis. First, we evaluated how factors related to characteristics and activities of the health micronetworks affect women's participation. The purpose of this analysis was to identify systemic factors that could plausibly explain any variability in women's screening participation rates across micronetworks. Second, we assessed the personal characteristics of women who were new users compared with women who had been screened within the preceding 5 years. Third, to understand how women learned of screening services, we carried out an analysis that allowed us to control for both micronetwork systemic factors and individual factors, since both influenced the participation of women in the screening program.

In the first analysis, the health micronetwork was the unit of analysis. We classified micronetworks according to the size of the population of women aged 25-49 years. Small micronetworks had fewer than 1300 women, midsized micronetworks had 1300 to 3999 women, and large micronetworks were urban areas with 4000 or more women in the eligible age group. The dependent variable for this analysis consisted of screening participation percentages for each micronetwork. Independent variables included indicators representing service accessibility, service availability, and intensity of promotional efforts. For service accessibility and availability, the indicators included the following: (1) number of mobile screening campaigns carried out in health micronetworks during the project, (2) presence or absence of screening services in the health network during the specified time period, and (3) ease of access to the nearest screening facility (transport, distance, time). We measured the intensity of promotional efforts through (1) the number of educational sessions led by promotion team members, (2) the number of sensitization events led by promotion team members, (3) the number of person-months of promotional activities, and (4) the number of advisory group meetings held during the project.

Since the ratio of promotion team to population was usually larger in smaller micronetworks than in midsized and large ones, we included the total eligible screening population for each micronetwork as an additional control factor. We combined data in a Microsoft Access 2000 (Microsoft Corporation) file and used SYSTAT 11.0 to carry out a backward stepping multiple regression analysis following steps outlined in SYSTAT's manual. The significance level was set at $p \leq 0.01$. In the model, we used log transformations for advisory group activity levels, education sessions, personmonths of promotional activities, and number of mobile campaigns. Because preliminary analysis showed that colinearity between micronetwork size and the number of mobile campaigns was high and micronetwork size was a more favorable model candidate, we dropped the number of mobile campaigns. We used principal components analysis to treat colinearity problems seen with the number of educational sessions and the number of person-months of promotional activities. These two variables yielded high factor loadings (0.941), formed a highly reliable scale (Cronbach's $\alpha=0.87$ ), and were combined to create a single scale measuring the intensity of educational promotion activities. Higher scores represent higher promotional activity levels. No analysis for systemic factors was possible for urban micronetworks, since there were only five.

The second step consisted of estimating the odds of participation for new users. We defined as "regular users" women who reported having been screened in the preceding 5 years; we defined them as "new users" if they had not been screened during the preceding 5 years or if they had never been screened. We compared regular and new users according to sociodemographic characteristics, reproductive health history, and use of health services for contraception, using odds ratios to approximate the relative risk of being a new user. We conducted univariate analysis using $\chi^{2}$ for categorical variables and a $t$-test for continuous ones, accepting an $\alpha$ error of 0.01 , given the size of the population studied. On the basis of these results, we examined the associations among variables and status (being a new user) for possible confounding and adjusted accordingly, using logistic regression to estimate odds ratios and 95\% confidence intervals (CI). We used Stata 9.0 for these analyses.

The guidelines of the Ministry of Health indicate that screening should start at age 30 , but a preliminary analysis showed that $77 \%$ of women below age 30 reported being screened in the preceding 5 years, thereby complicating our definition of regular users. According to guidelines, women not screened before age 30 should not be considered new users because they were not yet officially eligible, but the prevailing practice was to screen all women of reproductive age. We first excluded from analysis women under age 30 not screened in the preceding 5 years and then included them as regular users.

In both cases, results did not differ significantly from considering women in this age group in the same manner as in other age groups, according to their reported screening history. Therefore, we present the analysis with the same definition of new and regular users applied consistently across age groups. Within the new users group, we compared neverscreened women with those who were screened previously, but not within the last 5 years, on all sociodemographic and reproductive health variables. Since they did not differ significantly in any of the variables (data not shown), we pooled the never and infrequently screened and defined both as new users.

In the third step, we used fixed-effects conditional logistic regression to assess how women learned about screening services. This model accounts for the factors at the micronetwork level and at the same time lets us control for factors associated with being a new user at the individual level, hence decreasing bias in the comparison of the different ways women learned about screening services.

\section{RESULTS}

During the period beginning 1 November 2000 through 31 October 2003, 36759 women attended cervical cancer screening services in the region of San Martin, Peru. Overall, 32.3\% of the 107683 women ages 25-49 were screened, less than half of the expected $80 \%$ participation rate. The number of women 
FIGURE 1. Progress of screening coverage in San Martin, Peru, November 2000-October 2003

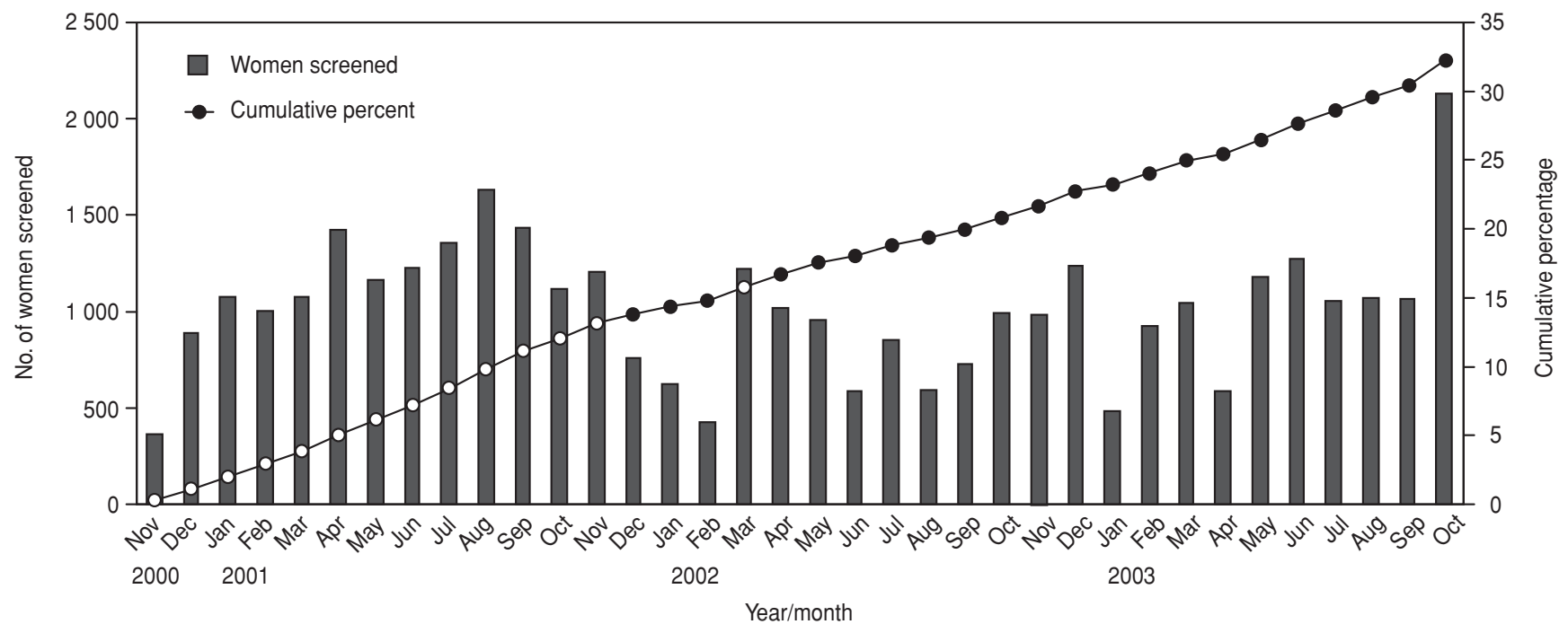

screened per month varied throughout the period (Figure 1). Fewer women were screened in the first and second months of the project, as clinics were incorporating visual inspection into their services. In the subsequent months, health services screened an average of 1022 women per month. Screening activity increased steadily from November 2000 through August 2001, decreased slightly in October 2001, and continued to decrease in December 2001, reaching its lowest level in February 2002 when only 424 women were screened.

A dengue outbreak in the main cities of the region peaked in January 2002. At the same time, a yellow fever epidemic and heavy rainfall challenged public health control of these vector-borne diseases in San Martin; health authorities instructed staff to prioritize dengue and yellow fever control efforts over all other activities. In March, screening activity increased again but followed an irregular pattern during the year. As in the previous year, in January 2003 a new yellow fever outbreak and flooding coincided with decreased screening activity. A campaign to complete activities at the end of the study period resulted in a large increase in the number of women screened in the last month.

Overall, 12208 (33.2\%) women were new users, of whom 7056 had never been screened and 5152 reported previous screening but not within the past 5 years. Participation was slightly higher in midsized micronetworks $(35.5 \%)$ than in urban $(30.7 \%)$ and small $(30.0 \%)$ micro- networks (Table 1). In small micronetworks, almost $40 \%$ of women screened were new users and $22.1 \%$ had never been screened before. Conversely, large micronetworks in urban areas screened a higher proportion of women who had also been screened in the preceding year. Thirty-eight of a total of 57 micronetworks had screening facilities or static services; most of these services were located in midsized and urban micronetworks. Overall, small micronetworks were poorly served by both static and mobile services. In addition, the average number of promotional activities was lower in small micronetworks than in midsized and urban micronetworks.

Results from the multivariate analysis showed two main effects on participation totals that explained 32\% (adjusted $R^{2}$ ) of the overall variance of participation. First, the intensity of education session activity levels carried out at the micronetwork level had a positive effect on participation totals (coefficient $=6.036$, 95\% CI $=2.782-9.290, p<0.001$ ). Second, the availability of static screening services in the micronetwork positively affected participation totals (coefficient = $10.824,95 \% \mathrm{CI}=3.447-18.202, p<0.005)$. The rest of the variables did not contribute significantly. These results should be treated cautiously since $68 \%$ of the variance found in the dependent variable was not explained by variables examined in this analysis.

In the analysis at the individual level, we found that new users tended to be older than regular users, but the dif- ference was not significant once we accounted for parity, years of education, and visits to health centers for contraception. The odds of being a new user decreased significantly as years of education increased (Table 2). In addition, after adjusting for other factors, women who had never visited health centers for family-planning services were 1.5 times more likely to be new users than were women who regularly visited health centers. For highly multiparous women (seven or more live births), the odds of being a new user did not differ from those of nulliparous women; yet women with one to six children were significantly less likely to be screened.

A total of 32839 participants (89.3\%) reported how they learned of the availability of screening services; among these women 11312 (34.4\%) were new users. After adjusting for micronetwork attended, history of use of familyplanning services, and years of education new users were more likely to report having heard of screening services through contact with health care providers or with a member of the TATI team, although results were marginally significant only for the latter (Table 3).

\section{DISCUSSION}

In the 3-year period studied, the program achieved participation of $32.3 \%$ of women ages 25-49 years. To be consistent with Ministry of Health guidelines in Peru that recommend a 3-year interval for cervical cancer screening, at least 
TABLE 1. Coverage and promotion activities across different-sized micronetworks, San Martin, Peru, 2000-2003

\begin{tabular}{|c|c|c|c|c|}
\hline & $\begin{array}{l}\text { Small } \\
\text { micronetworks }\end{array}$ & $\begin{array}{l}\text { Midsized } \\
\text { micronetworks }\end{array}$ & $\begin{array}{l}\text { Large urban } \\
\text { micronetworks }\end{array}$ & Total \\
\hline Eligible population (census 2000) & $29168(29$ 283) & 42736 (42 738) & 41820 (41 822) & 113724 \\
\hline \multicolumn{5}{|l|}{ Participation } \\
\hline $\begin{array}{l}\text { Women newly screened } \\
\text { (never screened as percent of screened) }\end{array}$ & $\begin{array}{l}8761(30.0) \\
1933(22.1)\end{array}$ & $\begin{array}{r}15150(35.5) \\
2907(19.2)\end{array}$ & $\begin{array}{r}12848(30.7) \\
2036(15.9)\end{array}$ & $\begin{array}{r}36759 \\
6876\end{array}$ \\
\hline \multicolumn{5}{|l|}{ Total new users } \\
\hline (as percent of women screened) & $3477(39.7)$ & $4877(32.2)$ & $3854(30.0)$ & 12208 \\
\hline $\begin{array}{l}\text { Women screened previous year } \\
\text { (percent of women screened) }\end{array}$ & $1082(12.4)$ & $2596(17.1)$ & $2587(20.1)$ & 6265 \\
\hline \multicolumn{5}{|l|}{ Service access and availability } \\
\hline Total micronetworks & 32 & 19 & 6 & 57 \\
\hline Total micronetworks with screening & & & & \\
\hline $\begin{array}{l}\text { tacilities (static services) } \\
\text { Average mobile screening campaigns (range) }\end{array}$ & $\begin{aligned} 6(18.8 \%) \\
11.6(3-30)\end{aligned}$ & $\begin{array}{r}16(84.2 \%) \\
26.7(10-67)\end{array}$ & $\begin{array}{c}6(100 \%) \\
47.1(22-99)\end{array}$ & 28 \\
\hline \multicolumn{5}{|l|}{ Access to nearest screening facility } \\
\hline Micronetworks with poor access & 10 & 2 & 0 & 12 \\
\hline Micronetworks with good access & 17 & 15 & 5 & 37 \\
\hline \multicolumn{5}{|l|}{ Community-based promotional efforts } \\
\hline Average advisory group meetings (range) & $5.0(0-21)$ & $7.3(0-48)$ & $4.7(0-15)$ & \\
\hline Average educational sessions led by & & & & \\
\hline promotion team members (range) & $54.8(15-181)$ & $103.3(11-354)$ & $171.7(108-301)$ & \\
\hline Average sensitization events (range) & $15.6(2-34)$ & $38.1(16-116)$ & $81.0(36-114)$ & \\
\hline $\begin{array}{l}\text { Average person-months promotional } \\
\text { activities (range) }\end{array}$ & $88.6(65-163)$ & $125.1(70-329)$ & $172.8(76-447)$ & \\
\hline
\end{tabular}

a Descriptive variables for large micronetworks are presented for comparison purposes.

2300 women should have been screened every month to achieve $80 \%$ participation. This level of screening was observed only in 2 of the 36 months studied. Competing demands on health personnel, in the form of other campaigns or outbreak responses, coincided with some of the most obvious drops in screening rates during the period.

Our analysis of systemic factors revealed that community promotional activities and the presence of static screening services are important for screening participation. Static screening services, however, are found mostly in midsized health micronetworks. At the individual level, lower levels of education and low utilization of health centers for family planning are independently associated with being a new user, thus pointing toward a vulnerable population in which screening could be increased. Reinforcing the role that health services play in women's decision to be screened, new users were slightly more likely to have learned of screening services through health care staff.

In this study, we used only information that would have been collected through routine health services and did not interview women who were not screened. Nonetheless, population surveys conducted in Latin America show
TABLE 2. Association between women's characteristics and being a new user, San Martin, Peru, 2000-2003

\begin{tabular}{|c|c|c|c|c|}
\hline Characteristic & $\begin{array}{l}\text { Regular } \\
\text { users } \\
\text { (percent) }\end{array}$ & $\begin{array}{c}\text { New } \\
\text { users } \\
\text { (percent) }\end{array}$ & $\begin{array}{l}\text { Adjusted } \\
\text { odds ratio } \\
\text { for new } \\
\text { user }\end{array}$ & $95 \% \mathrm{Cl}$ \\
\hline Total & 24551 & 12208 & & \\
\hline \multicolumn{5}{|l|}{ Age } \\
\hline $25-29^{a}$ & 28.9 & 28.9 & 1.0 & \\
\hline $30-34$ & 26.8 & 23.3 & 0.85 & $0.79-0.90$ \\
\hline 35-39 & 21.7 & 20.2 & 0.82 & $0.76-0.89$ \\
\hline $40-44$ & 14.1 & 15.2 & 0.84 & $0.77-0.93$ \\
\hline $45-49$ & 8.5 & 12.4 & 0.88 & $0.78-1.00$ \\
\hline \multicolumn{5}{|l|}{ Years of education } \\
\hline None & 4.6 & 9.0 & 4.34 & $3.53-5.33$ \\
\hline $1-2$ & 6.8 & 10.6 & 3.16 & $2.63-3.78$ \\
\hline $3-5$ & 29.3 & 31.9 & 2.06 & $1.83-2.31$ \\
\hline $6-8$ & 23.1 & 23.3 & 1.95 & $1.73-2.19$ \\
\hline $9-11$ & 25.1 & 19.0 & 1.50 & $1.36-1.66$ \\
\hline $12+^{a}$ & 11.1 & 6.2 & 1.0 & \\
\hline \multicolumn{5}{|c|}{ Visit health services for family planning } \\
\hline Yes $^{a}$ & 44.4 & 36.0 & 1.0 & \\
\hline No & 55.6 & 64.0 & 1.51 & $1.43-1.59$ \\
\hline \multicolumn{5}{|l|}{ Parity } \\
\hline None ${ }^{a}$ & 1.9 & 3.4 & 1.0 & \\
\hline $1-2$ & 35.5 & 27.7 & 0.45 & $0.39-0.52$ \\
\hline $3-4$ & 37.0 & 34.9 & 0.52 & $0.44-0.62$ \\
\hline $5-6$ & 15.9 & 18.6 & 0.59 & $0.46-0.76$ \\
\hline $7-8$ & 6.4 & 9.2 & 0.83 & $0.60-1.14$ \\
\hline $9-10$ & 2.3 & 4.1 & 1.07 & $0.68-1.68$ \\
\hline $11+$ & 1.0 & 2.1 & 1.17 & $0.65-2.09$ \\
\hline
\end{tabular}

a Reference category to estimate odds ratio. 
TABLE 3. How women learned of screening services, comparing new users with regular users, San Martin, Peru, 2000-2003

\begin{tabular}{lcccc}
\hline & $\begin{array}{c}\text { Number of } \\
\text { women }\end{array}$ & Odds ratio $^{\mathrm{a}}$ & $95 \% \mathrm{Cl}$ & $p$-value \\
\hline Attended an educational session & 14009 & 0.99 & $0.79-1.25$ & 0.94 \\
Contact with another provider & 8465 & 1.20 & $0.99-1.46$ & 0.07 \\
Neighbor, friend, or media & 5954 & 1.00 & $0.70-1.45$ & 0.98 \\
Contact with member of TATI team & 4411 & 1.28 & $1.00-1.65$ & 0.05 \\
\hline
\end{tabular}

a Odds ratios adjust for size of micronetwork, presence of static services, history of using family-planning services, and years of education.

that women reporting not being screened in the past 5 years were of lower socioeconomic status, had fewer years of schooling, and had less access to health services than screened women (6-12). Internationally, educational attainment and lack of access to or use of health services have been consistently reported as significant predictors of not attending screening services (1). Qualitative studies in six countries in Latin America identified three main reasons for not having been screened or for being behind schedule: (1) poor access to health services; (2) having priorities other than attending preventive services; and (3) fear of cancer, which is perceived as a fatal disease $(13,14)$.

A study comparing Latinas and white non-Latinas in the United States found that being Latina was only a minor predictor of use of screening after adjusting for socioeconomic status, which suggests a very limited role of "cultural factors"

International Agency for Research on Cancer, World Health Organization. Handbooks of cancer prevention. Vol. 10: cervix cancer screening. Lyon: IARC Press; 2005.

2. Marrett LD, Robles S, Ashbury FD, Green B, Goel V, Luciani S. A proposal for cervical screening information systems in developing countries. Int J Cancer. 2002;102(3):293-9.

3. Lewis MJ. A situation analysis of cervical cancer in Latin America and the Caribbean. Washington, D.C.: Pan American Health Organization; 2004.

4. Gage JC, Ferreccio C, Gonzales M, Arroyo R, Huivin M, Robles SC. Follow-up care of women with an abnormal cytology in a low-resource setting. Cancer Detect Prev. 2003; 27(6):466-71.

5. Luciani S, Winkler J. Cervical cancer prevention in Peru: lessons learned from the TATI demonstration project. Washington, D.C.: Pan American Health Organization; 2006.

6. de Quadros CA, Victora CG, da Costa JS. Coverage and focus of a cervical cancer preven- and endorses the association of lower socioeconomic status with lack of screening (15). The similarities of our findings with other studies in Latin America and in Latino populations support our assumption that women who were new or infrequent users represent a group of women likely not to be screened.

A caveat of our study is that "previous pap smear" was assessed via questionnaire. No corroboration in medical records was possible. Hence, the study is subject to the well-documented (16-20) recall bias typical of survey data. However, there is no reason to believe that recall bias would have systematically affected our results.

In San Martin, screening was offered free of charge and was integrated into existing primary care services. Midwives who performed screening were responsible for other programs as well. Other large studies evaluating cervical cancer screening have provided special incen-

\section{REFERENCES}

tion program in southern Brazil. Rev Panam Salud Publica. 2004;16(4):223-32.

7. Aguilar-Perez JA, Leyva-López AG, AnguloNájera D, Salinas A, Lazcano-Ponce EC. Tamizaje en cáncer cervical: conocimiento de la utilidad y uso de citología cervical en México. Rev Saude Publica. 2003;37(1):100-6.

8. Torres-Mejia G, Salmerón-Castro J, TéllezRojo MM, Lazcano-Ponce EC, Juárez-Márquez SA, Torres-Torija I, et al. Characteristics of respondents to a cervical cancer screening program in a developing country. Arch Med Res. 2002;33(3):295-300.

9. Iván Lucumí Cuesta D, Gómez Gutiérrez LF. Accesibilidad a los servicios de salud en la práctica de citología reciente de cuello uterino en una zona urbana de Colombia. Rev Esp Salud Publica. 2004;78(3):367-77.

10. Lamadrid Alvarez S. Knowledge and fears among Chilean women with regard to the Papanicolaou test. Bull Pan Am Health Organ. 1996;30(4):354-61. tives to and relied on dedicated personnel offering screening services in low resource settings $(21,22)$. Since our objective was to identify the problems that occur in "real life conditions," we did not provide any payments to health personnel, nor did we have fully dedicated clinical staff. Therefore, we consider that the level of participation achieved is close to the real potential of the region, should resources remain similar.

What prompted new users to participate in TATI is not fully clear. However, the marginally significant role of TATI team members and contact with health care providers along with the presence of static services in the first analysis highlight the importance of health services in attracting women to new services.

The program demonstrated its ability to draw in new users not previously reached by cytology-based services, yet it remains important to improve participation of women of low educational status and of those who do not visit health services regularly. These women represent a vulnerable group, who are precisely the ones most in need of cervical cancer screening, and we have yet to find more ways to reach them effectively.

Disclaimer. The findings, interpretations, and conclusions expressed in this paper are entirely those of the authors and do not represent the views of the World Bank, its executive directors, or the countries they represent.
11. Pinho Ade A, Franca Junior I, Schraiber LB, D'Oliveira AF. Cobertura e motivos para a realização ou não do teste de Papanicolaou no Município de São Paulo. Cad Saude Public. 2003;19(Suppl2):S303-13.

12. Brenna SM, Hardy E, Zeferino LC, Namura L. Conhecimento, atitude e prática do exame de Papanicolaou em mulheres com câncer de colo uterino. Cad Saude Publica. 2001;17(4): 909-14.

13. Lazcano-Ponce EC, Castro R, Allen B, Nájera $\mathrm{P}$, Alonso de Ruiz PA, Hernández-Avila M. Barriers to early detection of cervical-uterine cancer in Mexico. J Womens Health. 1999;8(3): 399-408.

14. Agurto I, Bishop A, Sánchez G, Betancourt Z, Robles S. Perceived barriers and benefits to cervical cancer screening in Latin America. Prev Med. 2004;39(1):91-8.

15. Pérez-Stable EJ, Sabogal F, Otero-Sabogal R. Use of cancer-screening tests in the San Francisco Bay area: comparison of Latinos and 
Anglos. J Natl Cancer Inst Monogr. 1995;18: $147-53$.

16. Bowman JA, Redman S, Dickinson JA, Gibberd R, Sanson-Fisher RW. The accuracy of Pap smear utilization self-report: a methodological consideration in cervical screening research. Health Serv Res. 1991;26(1):97-107.

17. Johnson CS, Archer J, Campos-Outcalt D. Accuracy of Pap smear and mammogram selfreports in a southwestern Native American tribe. Am J Prev Med. 1995;11(6):360-3.

18. Laverty C, Thurloe J, Farnsworth A. The value of Medicare statistics in monitoring Pap smear screening. Screening versus non- screening smears: the role of the laboratory. Pathology. 1994;26(3):281-4.

19. Pizarro J, Schneider TR, Salovey P. A source of error in self-reports of Pap test utilization. J Community Health. 2002;27(5):351-6.

20. Suarez L, Goldman DA, Weiss NS. Validity of Pap smear and mammogram self-reports in a low-income Hispanic population. Am J Prev Med. 1995;11(2):94-8

21. Sankaranarayanan R, Rajkumar R, Arrossi S, Theresa R, Esmy PO, Mahé C, et al. Determinants of participation of women in a cervical cancer visual screening trial in rural south India. Cancer Detect Prev. 2003;27(6):457-65.
22. Gaffikin L, Blumenthal PD, Emerson M, Limpaphayom K, Royal Thai College of Obstetricians and Gynaecologists (RTCOG)/JHPIEGO Corporation Cervical Cancer Prevention Group. Safety, acceptability, and feasibility of a singlevisit approach to cervical-cancer prevention in rural Thailand: a demonstration project. Lancet. 2003;361(9360):814-20.

Manuscript received on 19 November 2007. Revised version accepted for publication on 4 August 2008.
RESUMEN

\section{Análisis de la participación de las mujeres en un programa de tamizaje de cáncer cervicouterino en Perú}

Palabras clave Neoplasias del cuello uterino, tamizaje masivo, accesibilidad a los servicios de salud, Perú.
Objetivos. Evaluar los factores sistémicos e individuales que influyen en la participación de las mujeres en un programa de tamizaje de cáncer cervicouterino.

Métodos. En noviembre de 2000 se implementó un nuevo programa de tamizaje de cáncer cervicouterino en la región de San Martín, Perú. En total, 107683 mujeres de 25 a 49 años eran elegibles para el tamizaje. Este informe cubre el período inicial desde el establecimiento del programa hasta el 31 de octubre de 2003. Se utilizaron los datos del sistema de información del programa para identificar los factores sistémicos y las características individuales que influían en la participación de las mujeres. Se realizó un análisis en tres etapas: se evaluaron los factores sistémicos a nivel de las microrredes o grupos de centros de salud, se estimaron las probabilidades de ser una nueva usuaria (nunca tamizada o no tamizada en los últimos 5 años) según las características sociodemográficas y se evaluó la vía por la que las mujeres habían conocido de la disponibilidad de los servicios de tamizaje, controlado por factores de influencia identificados en análisis previos.

Resultados. En el período de tres años, 36759 mujeres elegibles recibieron este servicio, para una tasa de participación de 32,3\%. Aunque la asistencia varió según la zona y el momento, el programa atrajo a 12208 nuevas usuarias. Las microrredes sanitarias con servicios de tamizaje estáticos tuvieron una mayor participación. Las nuevas usuarias tenían menor nivel educacional y utilizaban menos los servicios de planificación familiar que las mujeres que se habían realizado la prueba con regularidad. Sin diferencias en el resto de los factores, las nuevas usuarias habían oído sobre los servicios de tamizaje más frecuentemente de los trabajadores sanitarios que las usuarias habituales.

Conclusiones. En este escenario, la presencia de servicios de salud y el contacto con ellos influyeron en el aumento de la participación en el tamizaje de mujeres que nunca se habían realizado la prueba o no lo habían hecho en los últimos 5 años. 